\title{
How Children Observe the Universe
}

\author{
John Dunlop \\ Auckland Observatory, Box 24, 180 Auckland, New Zealand \\ johnd@stardome.org.nz
}

Received 1999 August 17, accepted 2000 May 4

\begin{abstract}
Children who visited Auckland Observatory and Stardome Planetarium in 1998 were surveyed on their ideas about the Earth, the Moon and the Sun. Widespread misconceptions similar to those found in other studies were revealed, however the single teaching session had an impact on children's ideas comparable to that of much longer interventions. Several ideas not reported previously were expressed. For example, two children drew a figure eight orbit for the Earth; circling the Sun during the day, and the Moon at night. Only one child of the 67 surveyed proposed the notion of day and night being caused by the Sun orbiting the Earth. This is in contrast to many other studies. A drawing based pre-post survey proved to be a convenient and powerful tool for revealing changing patterns in children's thinking. The literature surveyed indicated levels of misconceptions about astronomy among teachers and other adults that were nearly as great as those of the children being taught. It would seem a strategic move to provide teachers with sufficient training if they are required to teach astronomy at every level, as has happened with the New Zealand science curriculum. A comparison between different question types suggests that multiple-choice questions may underestimate the knowledge of younger children by over $300 \%$ when compared with interview responses. A drawing based question in this study generated up to $41 \%$ more correct responses than a multiple-choice question on the same topic.
\end{abstract}

Keywords: astronomy education—astronomy teaching—planetarium

\section{Introduction}

In this paper I will outline some of the patterns in children's views about the Earth-Moon-Sun system gathered during 1998 as part of a Masters degree thesis (Dunlop 1999), and suggest some improvements to teaching methods in this area. I surveyed 67 children aged between 7 and 14 from three schools that visited Auckland Observatory. The causes of night and day, seasons and moon phases were among the concepts presented in a planetarium program and discussed in front of rotating Earth-Moon-Sun models (Figure 1). The children completed a simple drawing based survey (see Table 1) the day before and after a visit to the Observatory. They are identified here by pseudonyms.

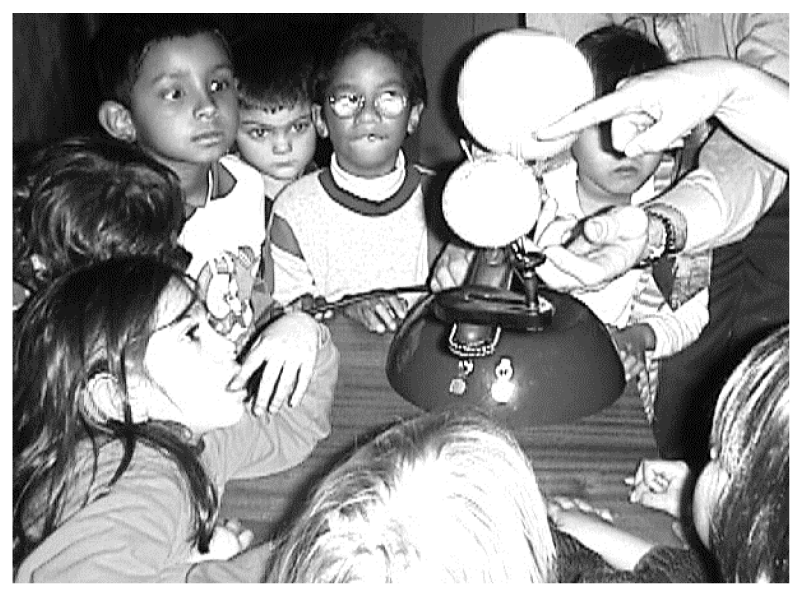

Figure 1-The Earth-Moon-Sun model used at Auckland Observatory.
Most children held views that were at variance in some way with accepted facts about the Earth-Moon-Sun system. The pattern of views expressed was broadly similar to that in other studies on children's ideas about astronomy (Baxter 1998; Broughton 1998; Comins 1998; Finegold \& Pundak 1990; Jones, Lynch \& Reesink 1987; Lightman \& Sadler 1993; Noble 1998; Nussbaum 1985; Osborne et al. 1994; Sharp 1999; Skamp 1994; Sneider \& Ohadi 1998; Stahly, Krockover \& Shepardson 1999; Taylor 1996; Vicentini-Missoni 1981; Vosniadou \& Brewer 1994). A selection of survey results that relate to the Earth, Moon and Sun are summarised in Tables 2 and 3.

\section{Children's Views}

\section{Children's Views of Day and Night}

Children were asked to 'Draw a picture in the space below to show why day-time and night-time happen.' A classic misconception held by young children is that the Sun orbits the Earth and yet only one child in this study held the idea. Two thirds drew a half-shaded Earth near the Sun, both before and after teaching (Figure 2). Several who drew this indicated that the Earth orbited the Sun daily. Several children had the Moon blocking the sunlight to cause night, and others had the Moon causing night in a similar way to the Sun causing day. Even after teaching only $20 \%$ of children explicitly mentioned the Earth spinning or drew it spinning. Several children made drawings that suggested they did not fully understand the way that light travels in straight lines from the Sun to the Earth. The depiction of dark shading right up to the edge of the Sun by two students suggests that they did not see light as radiating from the Sun throughout space (Figure 3). Brett, age ten, from 
Table 1. John Dunlop's survey

\section{ASTRONOMY SURVEY}

\section{First Name}

Class

Date

/ 1998 Age

Boy/Girl

I would like to find out your ideas about things in space. These questions will not be used to grade you in any way. Thank you for contributing-John Dunlop.

1a. Draw a picture of the Earth and the Sun in the space below to show why day-time and night-time happen. Include these labels: The Earth, The Sun, daytime, night-time

1b. Write a few words to explain your picture.

2a. Imagine you are out in space looking down on the Earth, the Moon and the Sun. Draw a picture to show how they would move-Show their orbits-Label each thing

2b. Write a few words to explain your picture.

3a. Janine looked for the Moon one week. Here is what she saw:

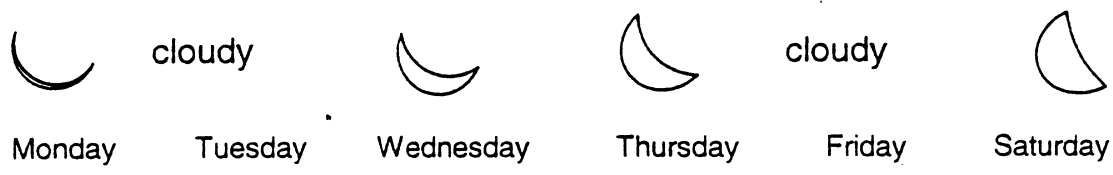

Use drawings to show why she saw the Moon these different shapes.

3b. Write a few words to explain your picture.

4a. Draw pictures of the Earth and the Sun to show why Summer and Winter happen.

4b. Write a few words to explain your picture.

5. Which statement explains why daylight and darkness occur on Earth? (Tick one box)

a. The Earth rotates on its axis.

b. The Sun rotates on its axis.

c. The Earth's axis is tilted.

d. The Earth revolves around the Sun.

Thank you for sharing your ideas

class four, maintained the incorrect explanation of the Moon blocking the sunlight even after teaching. It appears that he did not assimilate the idea of a half-lit
Earth, despite seeing three separate demonstrations of this effect, two in well-lit 3-D models, and one as a brief animation in the planetarium show. Maybe this is a 


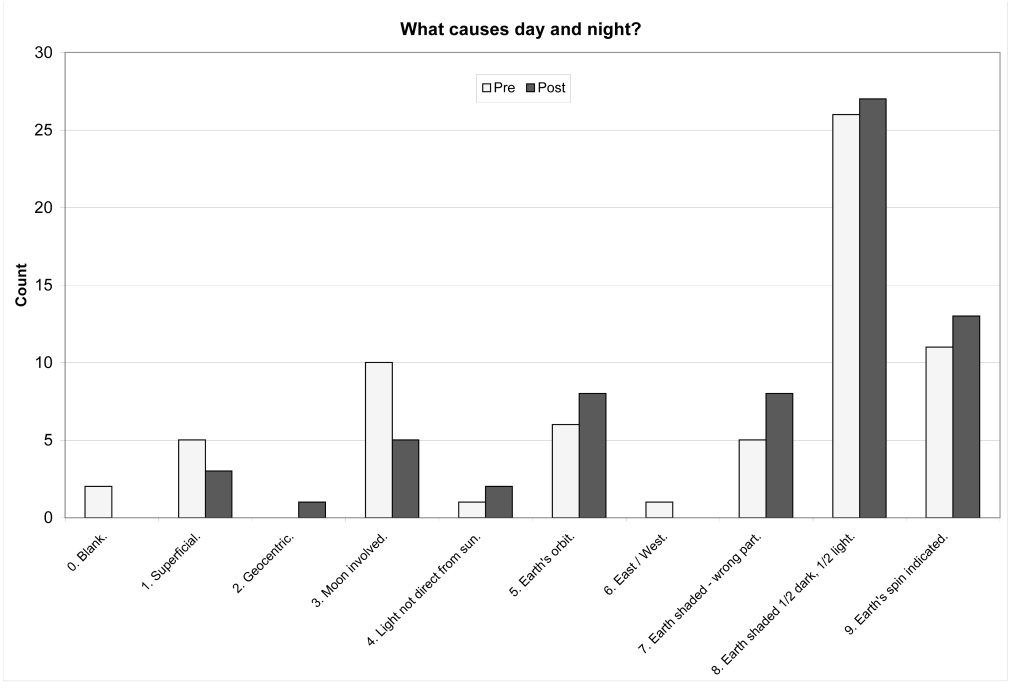

Figure 2-Day and night survey results.

Table 2. Research reported misconceptions at various levels (adapted from Philips 1991 and Skamp 1994)

Note that the age indicated is that for which research results have been reported; the misconceptions may persist to adulthood

Some astronomy misconceptions

Year K - 3

The Earth is sitting on something

The Earth is larger than the Sun

The Sun disappears at night

\section{Year 4-6}

The Earth is round like a pancake

We see because light brightens things

We do not live on the Earth; it is in the sky

Year 4-9

We live on the flat middle of a sphere

There is a definite up and down in space

Seasons are caused by the Earth's distance from the Sun

Phases of the Moon are caused by a shadow from the Earth

Phases of the Moon are caused by differing amounts of light reflected from the Earth

Different countries see different phases of the Moon on the same day

The Moon goes around the Earth in a single day

The Moon makes light in the same way the Sun does

The Sun is directly overhead at noon

The amount of daylight increases each day of summer

The Earth's revolution around the Sun causes night and day

Day and night are caused by the Sun going around the Earth

\section{Year 7 - college}

Gravity is selective; it acts differently or not at all on some matter Gravity increases with height

Gravity cannot exist without air

Gravity requires a medium to act through

Rockets in space require a constant force

\section{Adult}

The Sun goes around the Earth

The Sun goes around the Earth in less than a year

The Sun will never burn out

The Sun is not a star

The Universe contains only the planets in our solar system

Beings from another solar system have visited Earth

Tides are caused by the Moon orbiting the Earth every 24 hours consequence of Auckland's frequently cloudy weather, where sometimes there is no obvious connection between the Sun and daylight for weeks on end during winter.

The essential concept of the half-lit Earth spinning daily was not clearly demonstrated by most of the children, even after teaching. The design of the question did not make it easy for the children to express the fact that the Earth spins once a day. A better question might ask how the Earth and Sun move to make day and night happen.

\section{Children's Views of Orbits}

Children were asked to 'Imagine you are out in space looking down on the Earth, the Moon and the Sun. Draw a picture to show how they would move. Show their orbits. Label each thing.' The belief that the Moon orbits the Sun was expressed by $14 \%$ of the children (Figure 4). Three out of the eight 13 year-olds had this idea, and two of those held to the idea after teaching. The Earth's orbit as the cause of day and night was the choice of $9 \%$ before and $12 \%$ after teaching (Figure 2). An unusual misconception not previously reported was found, where two children had the Earth orbiting the Sun by day then the Moon by night in a figure eight pattern (Figure 5). The results from these questions suggest that the scientific view of Earth's orbit was by far the most popular among the children questioned, and that teaching had some effect on their ideas (Figure 6). However, in the multiple choice question (Table 1) $46 \%$ of the children chose the option that day and night were caused by the Earth going around the Sun (before teaching).

\section{Children's Views of Moon Phases}

Children were told 'Janine looked for the Moon one week'. Illustrations of moon phases over a week were given. The children were then asked to 'Use drawings in the space below to show why she saw the Moon these 


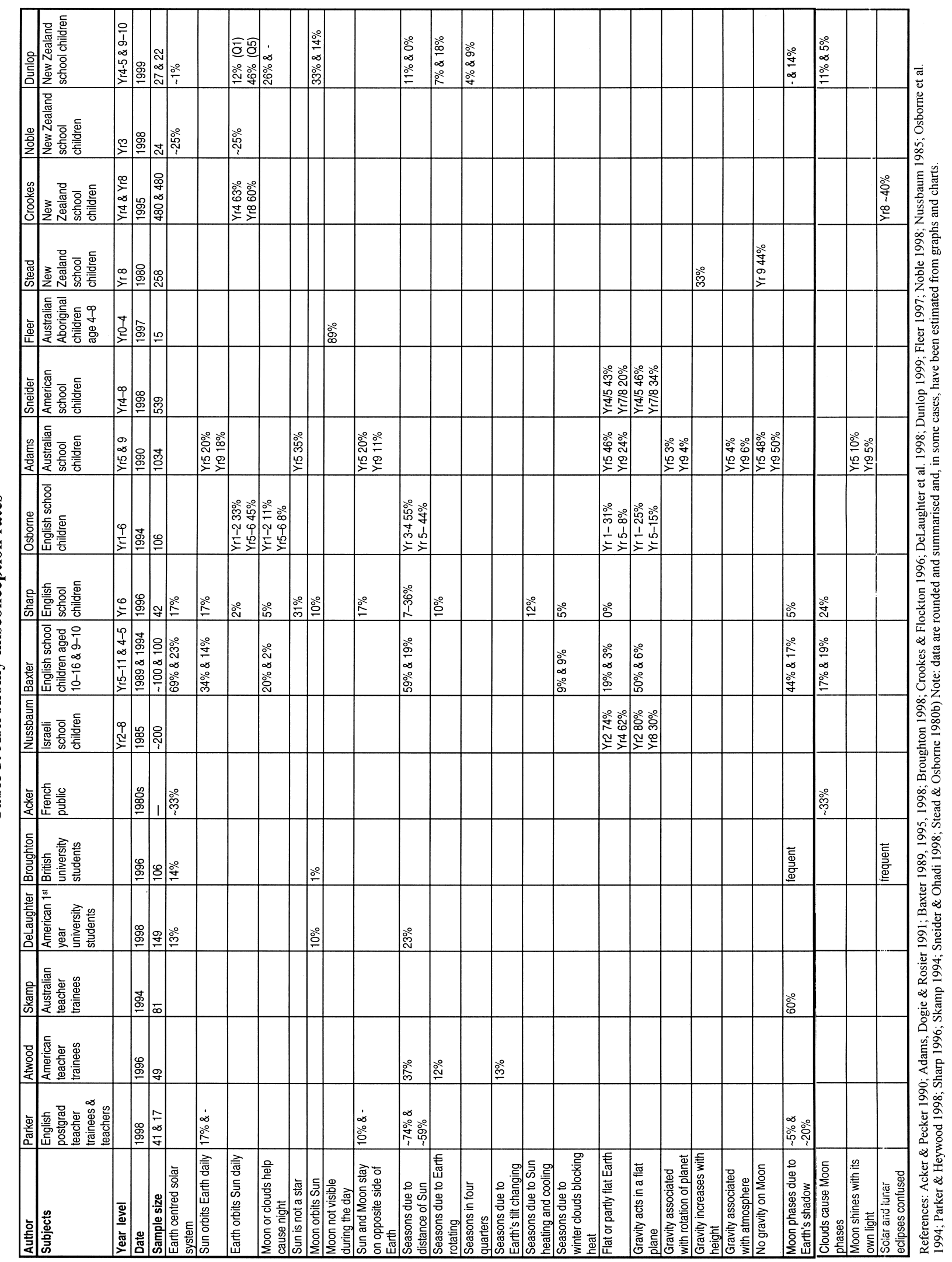


1a. Draw a picture of the Earth and the Sun in the space below to show why day-time and night-time happen. Include these labels: The Earth, The Sun, day-time, night-time

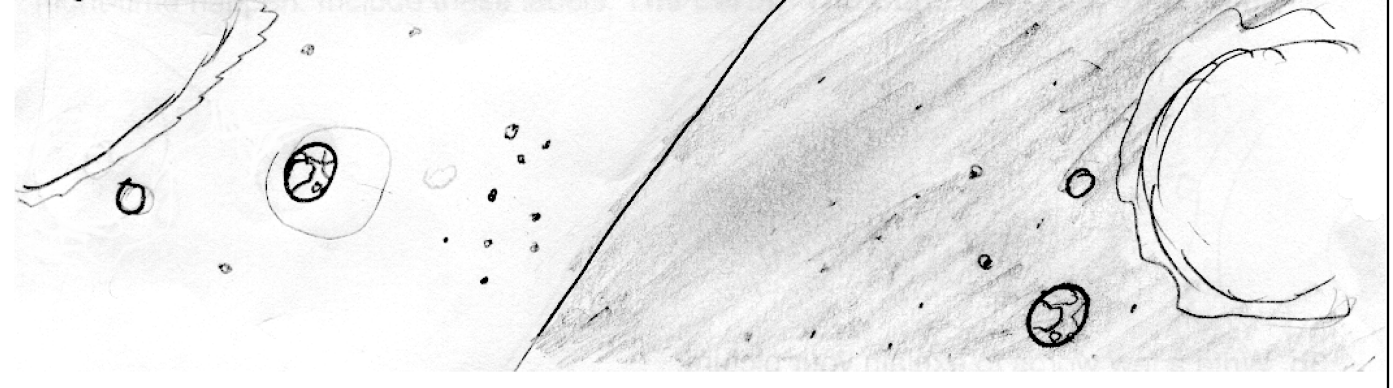

Figure 3-A 7-year-old explains the cause of night and day.

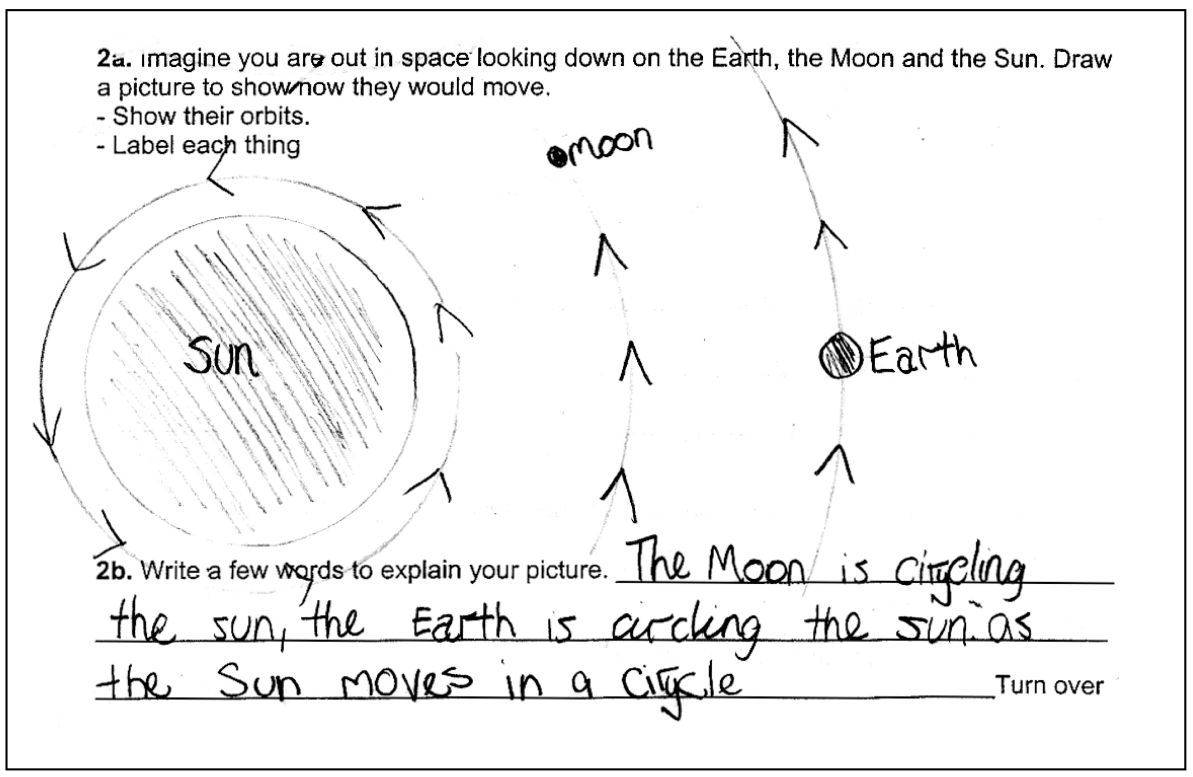

Figure 4-Neroli's view of how the Moon moves.

2a. Imagine you are out in space looking down on the Earth, the Moon and the Sun. Draw a picture to show how they would move.

- Show their orbits.

- Label each thing

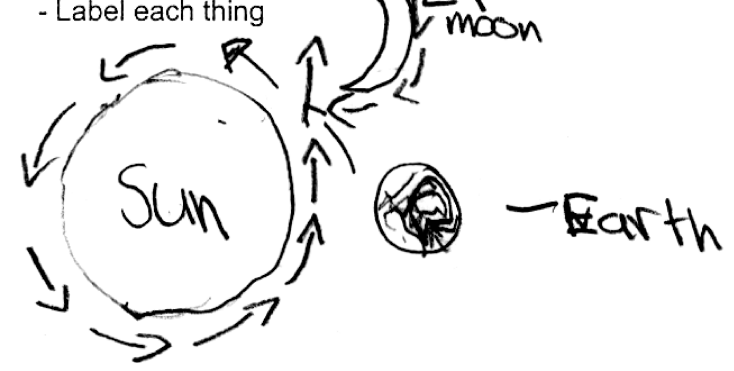

2b. Write a few words to explain your picture. The Earth does an orbit around the sun 24 hours and around the moon 12 hours. Turn over

Figure 5-Deidre's post-survey figure eight orbit drawing. 


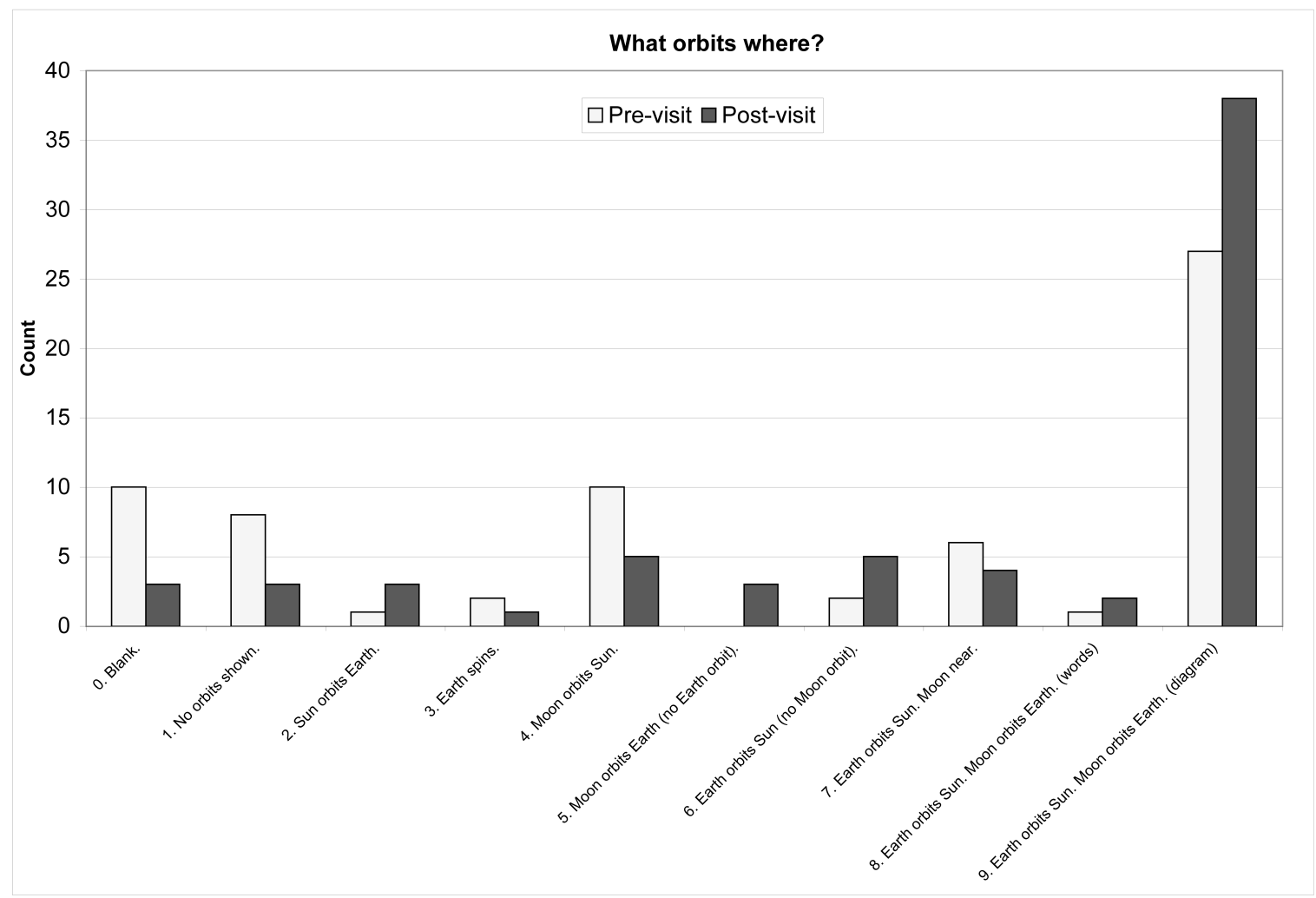

Figure 6-Orbit survey results.

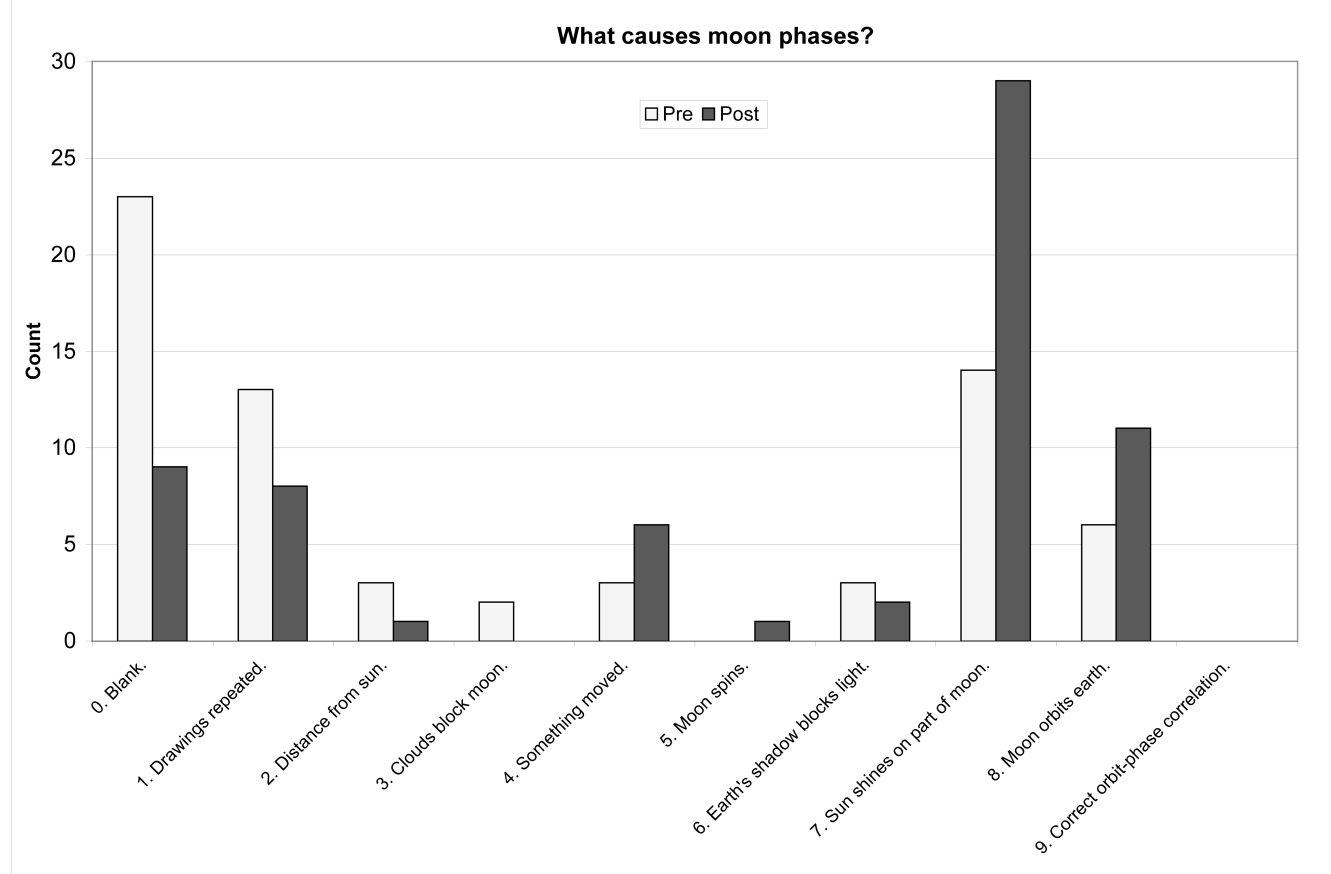

Figure 7-Moon phase survey results. 
3a. Janine looked for the moon one week. Here is what she saw:

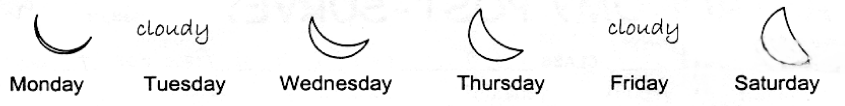

Use drawings in the space below to show why she saw the moon these different shapes.

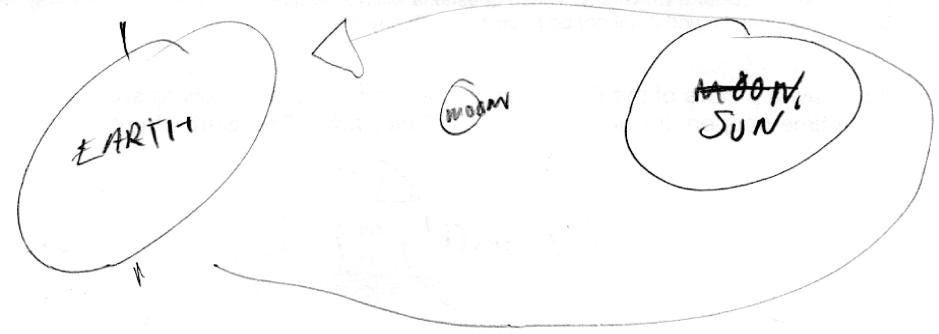

3b. Write a few words to explain your picture. the parth rotatel on its axis \& the moon rotates with the eaith around the sun. The san reflects light on the moon of thepe are

Figure 8-Megan's Moon phase explanation after teaching.

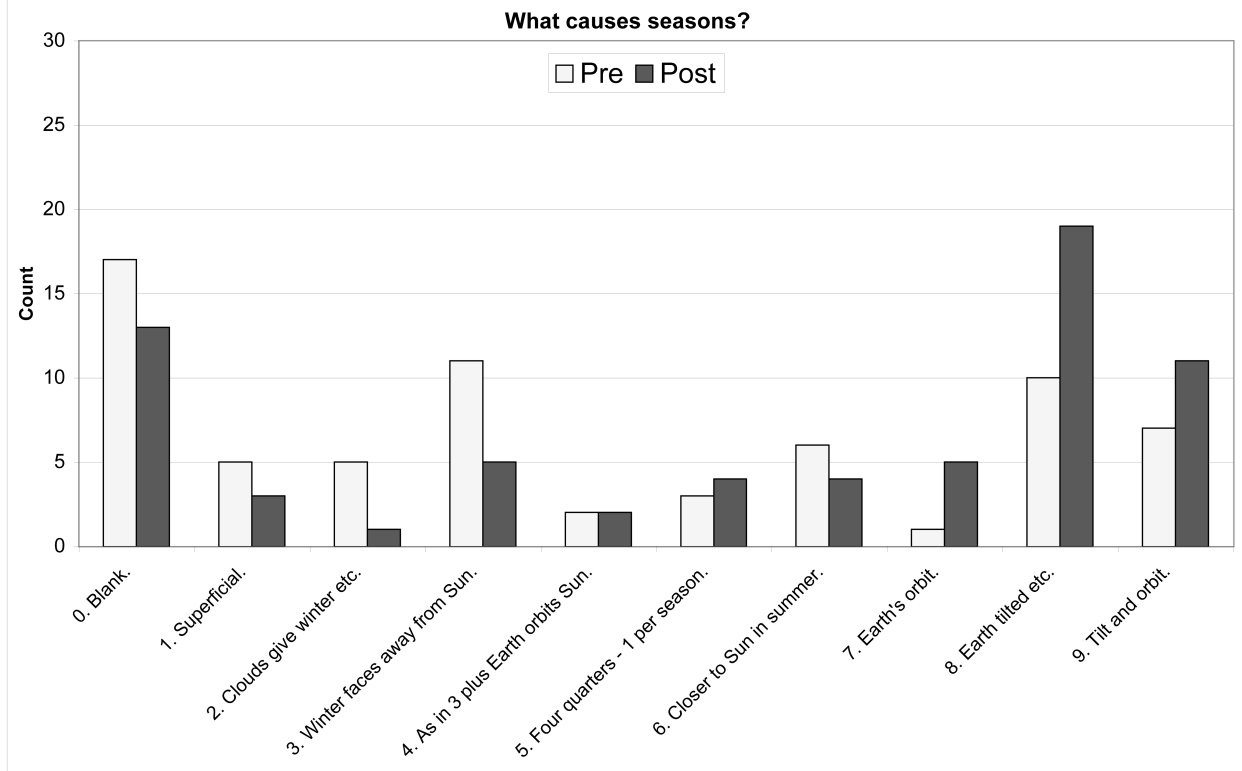

Figure 9-Seasons survey results.

4. Draw pictures of the Earth and the Sun to show why Summer and Winter happen.

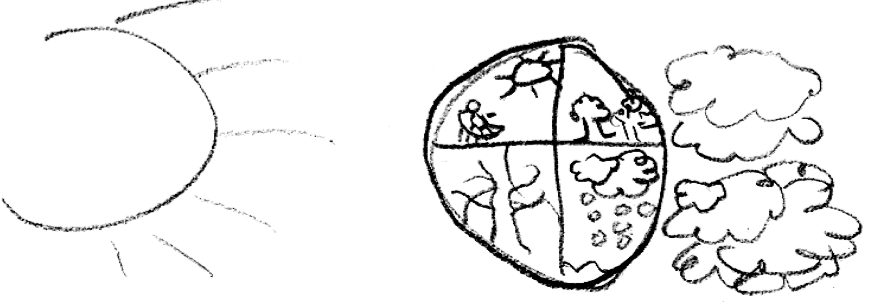

4b. Write a few words to explain your picture. beacuse the Eardh is move ing.

Figure 10-A quartered Earth as an explanation of seasons. 
different shapes'. The correct understanding of this phenomenon requires an understanding of the shading pattern on a sphere viewed from different angles compared to the light source, synthesised with a mental model of the Moon in orbit round a spherical Earth, viewed from the surface of the globe. This synthesis is rarely achieved, and may be too difficult for many younger children. The idea that phases are caused by the shadow of the Earth is common. Stahly, Krockover \& Shepardson (1999) reported rates of 70\%, 48\%, 38\% and $37 \%$ from various other studies.

Moon phases was the concept least understood in this study (Figure 7). Nobody correctly showed how the change in Sun-Earth-Moon angle caused particular phases, though some hinted at it. 'Megan', age 13, used a Sun-centred lunar orbit to explain Moon phases (Figure 8). She kept to her original lunar orbit after teaching but modified her view on the cause of Moon phases from a 'blocking' explanation to where the Earth's rotation gave different views of a Moon permanently between the Earth and the Sun. This was a rather reasonable deduction given the large Earth, small Moon and the closeness of the two in the diagram she drew which was no doubt derived from similar misleading diagrams in textbooks (DeBuvitz 1990) or the not-to-scale orrery used in the teaching episode (Figure 1). The idea of the Earth, clouds or something else blocking the light from reaching the Moon as the cause of Moon phases was popular, as other studies had shown. In this study, $13 \%$ held the 'blocking' view before teaching, and $12 \%$ held it after teaching. These results clearly indicate that this is a difficult concept for children to articulate. They suggest it might be appropriate to spend more time with clearly shaded scale 3D models of the Earth and Moon. This should establish the idea that viewing only part of the sunny half of the Moon is why we see phases, and that it depends only on the Sun-Earth-Moon angle.

\section{Children's Views of Seasons}

The children were asked to 'Draw pictures of the Earth and the Sun to show why summer and winter happen. Write a few words to explain your picture'. Many children found this question difficult, with $25 \%$ not attempting an explanation in their pre-test and $19 \%$ not answering in the post-test. Misconceptions found in other studies (Atwood \& Atwood 1996; Osborne et al. 1994; Parker \& Heywood 1998; Sharp 1996) were present in this group also. Cloud as the cause of winter was the choice for $7 \%$ before and $1 \%$ after teaching. Distance from the Sun was the choice of $9 \%$ before and $6 \%$ after teaching. Particularly pleasing was the large increase in the proportion of answers that involved the Earth's tilt or the combination of tilt and orbit as causing the seasons, from $25 \%$ before to $45 \%$ after teaching (Figure 9). The quartering of the Earth (Figure 10) was an interesting choice by a small group, most of whom kept the idea after teaching. Anecdotal evidence
Table 4. Marginal homogeneity (MH) tests on three level pre- and post-test scores

\begin{tabular}{lllll}
\hline$n=67$ & $\begin{array}{l}\text { Q1: Day } \\
\& \text { night }\end{array}$ & Q2: Orbits & $\begin{array}{c}\text { Q3: Moon } \\
\text { phases }\end{array}$ & Q4: Seasons \\
\hline Distinct values & 3 & 3 & 3 & 3 \\
Off-diagonal cases & 23 & 24 & 38 & 33 \\
Observed MH stat & 22 & 12 & 18 & 23 \\
Mean MH stat & 27.5 & 25.5 & 38.5 & 33.5 \\
Std dev. MH stat & 2.958 & 2.872 & 4.717 & 3.354 \\
Std MH statistic & 1.859 & 4.700 & 4.346 & 3.130 \\
Significance & $0.063 *$ & $0.000 * * *$ & $0.000 * * *$ & $0.002 * *$ \\
$\quad(2$ tailed) & & & & \\
\hline
\end{tabular}

* Significance at the $5 \%$ level; ** significance at the $1 \%$ level; and $* * *$ significance at the $0.1 \%$ level.

suggests that books showing the round Earth divided into four quarters with the four seasons depicted may produce or reinforce this misconception.

The combination of Earth's tilt and yearly orbit produces the changing day length and sun angle, which in turn cause seasons. A full understanding of this concept is considered by some too difficult for most primary school children (Osborne et al. 1994). Seasons scored the worst in Sharp's (1996) study, with just $19 \%$ achieving a 'scientific understanding'. The use of large clearly shaded 3D models would seem most appropriate in teaching this topic. For Southern Hemisphere children it is most helpful to mount the globe with South up. The misconceptions commonly held by adults that seasonal heating and cooling are caused by the changing distance from the Sun due to tilt or our elliptical orbit need to be specifically addressed (Atwood \& Atwood 1996; Parker \& Heywood 1998).

\section{The Effect of Teaching}

The results reported here were gathered before and after an observatory visit during which the causes of night and day, seasons and moon phases were presented in a planetarium program and discussed in front of rotating Earth-Moon-Sun models. A three level categorisation, with broad 'no/some/good understanding' categories was collapsed from the ten categories presented in each of Figures 2, 6, 7 and 9 above and used for trend analysis. Responses with no significant content were rated ' 0 ', those with incorrect content were rated ' 1 ', and correct responses were rated ' 2 '. The marginal homogeneity $(\mathrm{MH})$ test, an adaptation of the chi-square method, was found suitable for analysing the non-linear categorical data gathered here. Results are presented in Table 4 . This test reveals a highly significant change in measured understanding for questions 2, 3 and 4. For question 1 the improvement was not significant at the $5 \%$ level. From this, it is reasonable to conclude that the teaching did have a significant effect on the children's understanding. Inspection of Figures 2, 6, 7 and 9 will show where the main changes occurred. 


\section{Related Concepts}

Children's ideas about force, motion, light and gravity underlie their ideas about the Earth, Moon and Sun. The following section considers these concepts in more detail.

\section{Force and Motion}

Understanding of the movement of celestial objects ultimately needs to include an appreciation of the forces involved. The idea that the same gravity force, which holds us on the ground also, pulls the planets into orbits around the Sun is not an intuitive one. Isaac Newton was hailed as a genius when he demonstrated such a connection. Children's ideas may feature force in several ways:

- as a living thing 'trying to fight its way upward against the will of gravity'

- as being required for motion to continue

- as being proportional to motion

- as being absent if a body is not moving

- as acting in the direction of motion (Gunstone \& Watts 1985).

To fully appreciate the orbital motion of planets and moons it is necessary to first understand that objects are attracted to each other by the force of gravity, that this force is significant if the objects are massive, and that it decreases as the distance between the bodies increases. The elliptical orbit then can be understood as caused by a central pull deflecting the orbiting object from what would otherwise be a straight path. An appreciation of the Earth as a massive spherical body is necessary in order to move from a primitive 'pulling down in a flat plane' view of gravity to the more correct 'gravity pulling to the centre of a massive body' view. Stead and Osborne (1980a) found only one in 42 New Zealand high school students who had the idea that all objects exert a gravitational force, but plenty who had ideas of gravity 'holding', bound up with ideas of it being connected with air pressing down and with an atmospheric shield that prevented things floating away. Several studies have found ideas of spin causing gravity or gravity getting stronger with height above the ground (Ruggiero et al. 1985; Stead \& Osborne 1980a; Vicentini-Missoni 1981). I have found it helpful to compare gravity to the pull of a magnet, where objects can be seen to 'stick' to a central body equally from any direction.

\section{The Nature of Light and Vision}

In order to correctly interpret the pattern of light and shadow which causes day and night, seasons and Moon phases it is necessary to appreciate the manner that light travels in straight lines. It is also important to understand that light is either emitted from a luminous source such as the Sun, or else diffusely reflected from a nonluminous object such as the Moon. Considerable evidence exists that young children do not often use this scientific model to explain how they see things. A recent longitudinal study (Selley 1996, p. 718) reported Year 4 student's views and found at least one third thought some kind of 'light' travelled from the eye to the visible object. Only one student out of 21 described light reflecting off an object and travelling to the eye. A year later half of the group stated that something was emitted from the eyes during the seeing process. Guesne (1985) found a similar pattern where children aged between 10 and 14 rarely expressed the idea of light moving through space, often thought it stayed near objects, sometimes did not associate diffused daylight with the Sun, and often attributed the eye with the power to send out light. Driver et al. (1994) surveyed research on this topic and found consistent reports of such misconceptions. For example, two studies found the idea that light did not travel very far in the daytime to be common (Fetherstonhaugh \& Treagust 1990; Stead \& Osborne 1980b).

\section{Adult's Ideas}

It is not just children who entertain misconceptions. Several studies report survey results with teacher trainees, university students and teachers. Lightman, Miller \& Leadbeater (1987) surveyed 1,120 American adults and found $45 \%$ believed the Sun was not a star. Ojala (1992) asked 86 primary school teacher trainees in Finland to state what was the most important factor affecting temperature differences around the Earth, and write a short essay with brief explanations of other factors. Only five trainees gave a completely correct answer. He found that misleading and not to scale diagrams in books caused the acquisition of incorrect concepts. Skamp (1994) recorded Australian teacher trainees' views on astronomical matters using the 'card sort' technique, where trainees agreed or disagreed with statements on cards. Only $40 \%$ disagreed with the statement that 'The Moon changes shape because of the varying amounts of the Earth's shadow cast upon it'. DeLaughter et al. (1998) reported results from testing students taking an introductory geology course at the University of Illinois. At least a quarter had deficient models of the Earth-Moon-Sun system, and over half could not explain the cause of seasons. Atwood and Atwood (1996) found only one of the 49 teacher trainees they studied gave a scientifically acceptable explanation for seasons. They found $50 \%$ attributed the seasons to the changing distance from the Sun in written responses yet only $37 \%$ used that explanation when interviewed with models of the Earth and Sun present. These examples suggest that one cause of children's misconceptions could be their teacher's incorrect ideas.

The studies reviewed above all revealed nonscientific conceptions, with many adults retaining misconceptions common among children (see Table 3). Several related concepts involving the nature of light, vision, reflection, gravity and the relative sizes, distances and motions of a spherical Earth, Moon and Sun in space are all required to synthesise a satisfactory explanation for phenomena such as Moon phases or 


\section{Table 5. Jonathon Osborne's survey: Common ideas in astronomy}

The following are all a selection of common ideas in astronomy. Some are true and some are not.

For each statement discuss whether it is true, false or you do not know.

For those that know the answer, make a note of what evidence you base your beliefs on.

\begin{tabular}{|c|c|c|c|c|c|c|c|c|c|}
\hline \multirow{2}{*}{\multicolumn{2}{|c|}{$\begin{array}{l}\text { Statement } \\
\text { It is hotter in summer as we are } \\
\text { nearer the Sun }\end{array}$}} & \multirow{2}{*}{\multicolumn{2}{|c|}{ Disagree }} & \multirow{2}{*}{\multicolumn{2}{|c|}{ Evidence }} & & & & \\
\hline & & & & & & & & & \\
\hline & & & & & The Earth is supported in space & & & & \\
\hline & & & & & $\begin{array}{l}\text { The Sun generates iits energy through } \\
\text { nuclear fusion }\end{array}$ & & & & \\
\hline & & & & & $\begin{array}{l}\text { A light year is how far light travelling } \\
\text { at } 300,000 \mathrm{~km} \text { per second would } \\
\text { travel in one year }\end{array}$ & & & & \\
\hline & & & & & $\begin{array}{l}\text { The seasons are caused because the } \\
\text { Earth's axis is tilted }\end{array}$ & & & & \\
\hline & & & & & $\begin{array}{l}\text { The Moon makes light the same way } \\
\text { the Sun does }\end{array}$ & & & & \\
\hline & & & & & Gravity increases with height & & & & \\
\hline & & & & & The Sun will never burn out & & & & \\
\hline & & & & & $\begin{array}{l}\text { There is a definite up and down in } \\
\text { space }\end{array}$ & & & & \\
\hline & & & & & $\begin{array}{l}\text { Beings from another solar system } \\
\text { have visited the Earth }\end{array}$ & & & & \\
\hline & & & & & The Sun goes around the Earth & & & & \\
\hline & & & & & $\begin{array}{l}\text { Different countries see different } \\
\text { phases of the Moon on the same day }\end{array}$ & & & & \\
\hline & & & & & Astrology is able to predict the future & & & & \\
\hline & & & & & $\begin{array}{l}\text { Planets cannot be seen with the } \\
\text { naked eye }\end{array}$ & & & & \\
\hline & & & & & $\begin{array}{l}\text { The Earth is molten apart from its } \\
\text { crust }\end{array}$ & & & & \\
\hline & & & & & The Earth is 3000 million years old & & & & \\
\hline & & & & & $\begin{array}{l}\text { The stars we see from the Southern } \\
\text { Hemisphere are the same as the ones } \\
\text { from the Northern Hemisphere }\end{array}$ & & & & \\
\hline
\end{tabular}

seasons. Thus, it is not surprising that most children and adults are unable to explain the phenomena correctly. The importance of adult misconceptions increases significantly when they become teachers.

\section{Teaching Tips}

Stella Vosniadou (1991) argued for the need to present concepts in suitable order, for example the cause of gravity first, then the spherical nature of Earth, then the 


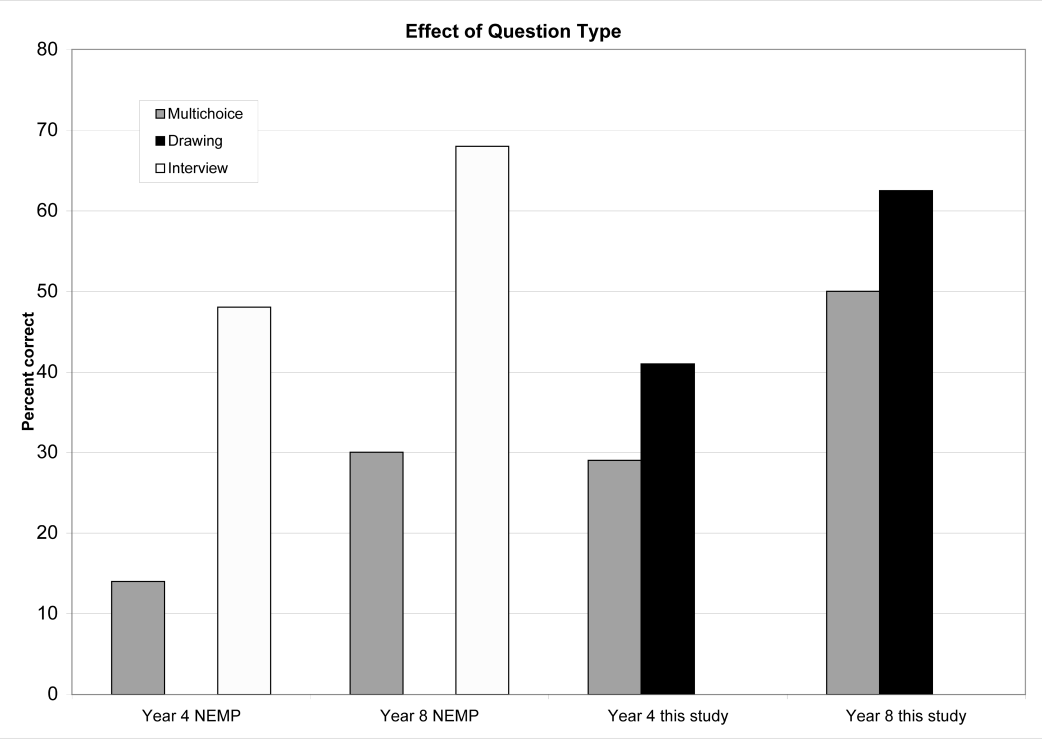

Figure 11-Influence of question type on correct response rate.

cause of day, night and so on. She based the strategy on her recognition of the existence of relatively few entrenched beliefs that underlie a large number of misconceptions. Her premise was that it was better to tackle the one underlying belief than try to deal with the many resulting misconceptions. She pointed out the need to give clear reasons to children for why scientific explanations are better than common misconceptions. For example, science teaches that the Sun is a star. However, in everyday experience it seems that the Sun is very different from stars. It is hot, bright, and associated with day while stars are faint and associated with cold nights. Until the great difference in distance is understood as the reason for this, statements about the Sun as a star will often not make sense to the learner. Vosniadou (1991, p. 235) also stressed the importance of encouraging children to reflect about their own thinking: 'Students often find scientific explanations incredible and see no reason why they should question their beliefs, which are more consistent with their everyday experience. It is important when we teach science to provide children with situations that will make them realise that their beliefs about the world are not 'true facts' but theoretical constructions which may be subject to falsification.'

\section{Teacher Training}

Parker \& Heywood (1998) produced a significant advance when they had teacher trainees and teachers on a ten day training course record their views about the Earth-Moon-Sun system as annotated diagrams, both before and after learning sessions. The sessions included teaching input about the Earth, Moon and Sun, practical three-dimensional modelling, discussion, together with written reflection about how their ideas were changing and which factors had contributed significantly to developing their understanding. The premise was that by becoming aware of their own struggles to learn the concept, they would be able to structure learning experiences for their students in a much more meaningful way.

Most New Zealand primary school teachers have had little astronomy experience, yet are now required to teach it at each level in the science curriculum. It would seem a strategic move to provide them with training. I have found three methods of in-service teacher training useful. A national one-week conference in Earth Science and Astronomy attracted a government subsidy, and 50 teachers attended. Weekend courses at a school campsite in a dark location have been held on several occasions and attracted nearly 100 teachers. They are cheap to run, allow intensive hands-on learning and do not disrupt school programs. They also have the advantage of modelling the type of astronomy teaching possible at school camps, where the difficulty of getting a class together in a dark and safe environment is not a problem. After school sessions for groups of teachers who are planning astronomy unit have also been popular.

\section{Model Manipulation}

A variety of dissimilar models of the Earth-Moon-Sun system can promote more rapid acquisition of correct concepts, because the helpful and unhelpful features of each model are easily appreciated when they are compared and contrasted. Scale models and threedimensional models seem particularly useful. These lead to mental models. Vosniadou (1991) helpfully categorised mental models as being constructed by the learner from underlying conceptual structures, and able to be grouped in three categories: intuitive, scientific (correct) and synthetic. The intuitive models are seen as generated by the learner from some environmental stimulus and the synthetic ones as hybrids generated when the learner attempts to accommodate some scientific model 
with their own existing knowledge. My suspicion is that many children do not get sufficient time to interact personally with realistic 3D models and that many discussions around the models that are used do not focus on the key reasons why shading patterns on the Earth and Moon occur.

\section{Identifying Misconceptions}

'Between the thought and the word spoken, between the word spoken and the word heard, between the word heard and the meaning taken, lies a vast gulf.'

Listening to every child's ideas about a topic before and after teaching is hardly practicable for most teachers. Before-and-after surveys provide an efficient way of doing this. The validity of written assessments is problematic (see the next section), but the evidence here suggests that drawing based surveys are useful. The survey used in this study is given in Table 1 . The 'Common Ideas' questionnaire given in Table 5 was developed by Jonathan Osborne, formerly of Kings College, London, and is used with his permission. One benefit of such a survey format is that misconceptions and correct statements are clearly displayed, along with the reasoning used.

\section{The Effect of Question Type}

In my study $29 \%$ of year 4 (8 and 9 year olds) and $50 \%$ of year 8 (13 year olds) chose the correct answer to a multiple choice question about the cause of day and night (Figure 11). When the same concept was tested by asking for a drawing and statement in question 1, 41\% of the year 4 and $62.5 \%$ of the year 8 received a 'good understanding' rating. This is evidence that question type influences the correct response rate. Further support for this view is found in the NEMP report (Crookes $\&$ Flockton 1996). During NEMP interviews in 1995, $48 \%$ of the year 4 children and $68 \%$ of the year 8 children correctly described the cause of day and night. However, only $14 \%$ of the year 4 children and $30 \%$ of the year 8 children correctly answered a written multiple-choice question about the cause of day and night. Together these results provide strong evidence that question type has a major bearing on the proportion of correct answers and that the interview question type is even more effective in eliciting correct responses than the drawing question type. In this case the multiple choice question (Table 1, Q5) appears to have underreported the number of correct responses and the result suggests that the extensive use of multiple choice with children of this age may be unwarranted.

\section{Conclusions}

My study showed an unusually low rate of the misconception that the Sun orbits the Earth (Figure 6). This could indicate successful teaching about the Earth and other planets orbiting the Sun in the New Zealand school system. However, it would seem that the cause of day and night is not so well taught in New Zealand if the high rates of the 'Earth orbits Sun daily' misconception are any guide (Figure 2). This could be a synthetic misconception, where elements of the scientific view are combined with intuitive ideas. Understanding about Moon phases and seasons is also not well developed (Figures 7 and 9). The evidence suggests that even a short period of high impact instruction can make a significant improvement in children's understanding. Unfortunately, many adults are likely to pass on their misconceptions to the next generation, rather than a distillation of the centuries of effort that have already been invested in improving knowledge about the Universe. Some practical suggestions that may improve teaching in this area are:

- Present children with realistic models of the Earth-Moon-Sun system or they may well incorporate the inaccuracies of teaching aids into their mental models.

- Beware of written test results - they may grossly under-report real understanding, especially in younger children. Try comparing children's 'before' and 'after' drawings instead, or have older children give reasons for their choices.

- Invest in improved teacher knowledge about astronomical matters, and teacher skills, that lead to meaningful learning.

- Listen to children and take their ideas seriously, or they will probably squeeze bits of adult explanations into their own unique view of how the Universe is.

\section{Acknowledgments}

Thank you to Lilian, my long-suffering wife, Lydia Austin, my thesis supervisor, the students and teachers who participated in the surveys, the staff at the Auckland Observatory and the National Education Monitoring Project, Ann-Marie Noble, Rodney Hicks, Stephen Walters, Ri Weal, and David Neil. Thank you to my children Hannah and David, who tolerated their father's never ending questions about what they thought and why they thought it. Thank you to the education experts who took the time to personally encourage me: Reinders Duit, David Treagust, Art Stinner, Jonathan Osborne, Ian Taylor, Bill MacIntyre, Chris Marston, Terry Crookes, Gerry Wellington, David Salter, Robin Dixon and John Hattie. Thank you also to the many others who took the time to publish their ideas whether in books, journals or on the wonderful World Wide Web.

\section{References}

Acker, A., \& Pecker, J. C. 1990, in The Teaching of Astronomy, ed. J. M. Pasachoff \& J. R. Percy (Cambridge Univ. Press), pp. 189-95 
Adams, R. J., Doig, B. A., \& Rosier, M. 1991, Science Learning in Victorian Schools: 1990, Australian Council for Educational Research Monograph 41 (Melbourne: ACER)

Atwood, R. K., \& Atwood, V. A. 1996, Preservice elementary teachers' conceptions of the causes of seasons. J. Res. Science Teaching, 33, 553-63

Baxter, J. 1989, Children's understandings of familiar astronomical events. Int. J. Science Education, 11, 502-13

Baxter, J. 1995, in Learning Science in the Schools. ed. S. M. Glynn \& R. Duit (Mahwah NJ: Lawrence Erlbaum)

Baxter, J. H. 1998, in New Trends in Astronomy Teaching, IAU Colloquium 162, ed. L. Gouguenheim, D. McNally \& L. R. Percy (Cambridge Univ. Press)

Broughton, M. P. V. 1998, in New Trends in Astronomy Teaching, IAU Colloquium 162, ed. L. Gouguenheim, D. McNally \& L. R. Percy (Cambridge Univ. Press)

Comins, N. F. 1998, in New Trends in Astronomy Teaching, IAU Colloquium 162, ed. L. Gouguenheim, D. McNally \& L. R. Percy (Cambridge Univ. Press)

Crookes, T., \& Flockton, L. 1996, National Education Monitoring Report 1-Science Assessment Results 1995 (1) (Dunedin: Educational Assessment Unit, University of Otago)

DeBuvitz, W. 1990, The importance of scale drawings. The Phys. Teacher (December)

DeLaughter, J. E., Stein, S., Stein, C., \& Bain, K. R. 1998, Rocks for jocks: Preconceptions about the Earth, Eos (August) (see http://www.earth.nwu.edu/people/seth/Test/astro.html)

Driver, R., Squires, A., Rushworth, P., \& Wood-Robinson, V. 1994, Making Sense of Secondary Science: Research into Children's Ideas (London \& New York: Routledge)

Dunlop, J. A. 1999, Changing children's astronomical ideas. MEd. thesis, University of Auckland

Fetherstonhaugh, T., \& Treagust, D. F. 1990, Students' understanding of light and its propagation following a teaching strategy to engender conceptual change. Proc. Conf. of the American Educational Research Association, Boston

Finegold, M., \& Pundak, D. 1990, Students' conceptual frameworks in astronomy. Aust. Science Teachers J., 36(2), 76-83

Fleer, M. 1997, A cross-cultural study of rural Australian Aboriginal children's understandings of night and day. Res. Science Education, 27, 101-16

Guesne, E. 1985, in Children's Ideas in Science, ed. R. Driver, E. Guesne \& A. Tiberghien (Milton Keynes: Open University Press), pp. 10-32

Gunstone, R., \& Watts, M. 1985, in Children's Ideas in Science, ed. R. Driver, E. Guesne \& A. Tiberghien (Milton Keynes: Open University Press), pp. 91-5

Jones, Lynch, \& Reesink 1987, Children's conceptions of the Earth, Sun and Moon. Int. J. Science Education, 9, 43-53

Lightman, A., \& Sadler, P. M. 1993, Teacher predictions versus actual student gains. Phys. Teacher, 31, 162-7

Lightman, A. P., Miller, J. D., \& Leadbeater, B. J. 1987 , Contemporary cosmological beliefs. Second Int. Seminar on
Misconceptions and Educational Strategies in Science and Mathematics

Noble, A. M. 1998, Using the history of science to teach astronomy in the primary school. MEd. thesis, University of Auckland

Nussbaum, J. 1985, in Children's Ideas in Science, ed. R. Driver, E. Guesne \& A. Tiberghien (Milton Keynes: Open University Press), pp. 171-92

Ojala, O. 1992, The third planet. Int. J. Science Education, 14, 191-200

Osborne, J., Wadsworth, P., Black, P., \& Meadows, J. 1994, The Earth in Space (Liverpool: Liverpool King's SPACE Project)

Parker, J., \& Heywood, D. 1998, The Earth and beyond: Developing primary teachers' understanding of basic astronomical events. Int. J. Science Education, 20, 503-20

Philips, W. C. 1991, Earth science misconceptions. The Science Teacher (February), 21-3

Ruggiero, S., Cartielli, A., Dupre, F., \& Vicenti-Missoni, M. 1985, Weight gravity and air pressure: Mental representations by Italian middle-school pupils. European J. Science Education, 7, 181-94

Selley, N. J. 1996, Children's ideas on light and vision. Int. J. Science Education, 18, 713-23

Sharp, J. G. 1996, Children's astronomical beliefs: A preliminary study of year 6 children in southwest England. Int. J. Science Education, 18, 685-712

Sharp, J. G. 1999, Teaching and learning astronomy in primary schools. School Science Review, 80(292), 75-85

Skamp, K. 1994, Determining misconceptions about astronomy. Aust. Science Teachers J., 40(3), 63-7

Sneider, C. I., \& Ohadi, M. M. 1998, Unraveling students' misconceptions about the Earth's shape and gravity. Science Education, 82, 265-84

Stahly, L. L., Krockover, G. H., \& Shepardson, D. P. 1999, Third grade students' ideas about the lunar phases. J. Res. Science Teaching, 36, 159-77

Stead, K., \& Osborne, R. 1980a, Gravity: LISP Working Paper 20 (Hamilton: Science Education Research Unit, University of Waikato)

Stead, B. F., \& Osborne, R. J. 1980b, Exploring student's concepts of light. Aust. Science Teachers' J., 26(3), 84-90

Taylor, I. J. 1996, Illuminating lunar phases. The Science Teacher (November), 39-41

Vicentini-Missoni, M. 1981, Earth and gravity comparison between adults' and children's' knowledge. Int. Workshop on Problems Concerning Students' Representation of Physics and Chemistry Knowledge, Pedagogische Hochshule, Ludwigsburg

Vosniadou, S. 1991, Designing curricula for conceptual restructuring: Lessons from the study of knowledge aquisition in astronomy. J. Curriculum Studies, 23, 219-37

Vosniadou, S., \& Brewer, W. F. 1994, Mental models of the day/ night cycle. Cognitive Science, 18, 123-84 